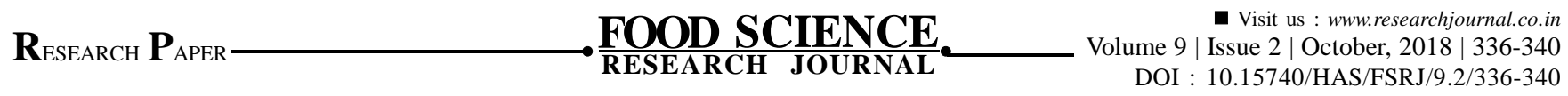

\title{
Optimization and quality evaluation of nutritious soup mix
}

\author{
Nivedita and Rita Singh Raghuvanshi
}

The study was undertaken with the objective to develop soup mix which is easy to make, takes less preparation time and is nutritious. It was made from finger millet (Eleucine coracana), horse gram flour (Macrotyloma uniflorum) and regional flavouring agent gandraini (Angelica glauca). Product optimization was done with different combination of ingredients and final level i.e. 46.5 per cent of finger millet flour, 12.0 per cent of horse gram flour, 9.0 per cent soybean, 10.5 per cent of salt, 9.0 per cent garlic and 1.0 per cent gandraini and 12.0 per cent oil were selected by sensory evaluation in nine point hedonic scale and product acceptability done by score card method. The soup mix was dried for investigation of nutritional composition, calcium and iron and results revealed that it was highly nutritious in all the parameters along with being accepted by population.

Key Words : Soup mix, Flavoring agent, Finger millet, Horse gram flour, Gandraini

How to cite this article : Nivedita and Raghuvanshi, Rita Singh (2018). Optimization and quality evaluation of nutritious soup mix. Food Sci. Res. J., 9(2): 336-340, DOI : 10.15740/HAS/FSRJ/9.2/336-340. Copyright@ 2018: Hind Agri-Horticultural Society. 